\title{
Nitrificación En La Estabilización De Residuos Líquidos En Un Reactor Batch Aireado Completamente Mezclado
}

\author{
Ing. Agustín Leiva Pérez, PhD \\ Ing. David W. Moreira Vera, M.Sc. \\ Ing. Joffre A. Andrade Candell, M.Sc. \\ Q.F. Ana María Aveiga Ortiz, M.Sc. \\ Ing. Julio A. Loureiro Salabarría, M.Sc. \\ Docentes - Investigadores de la Escuela Superior \\ Politécnica Agropecuaria de Manabí - MFL
}

doi: 10.19044/esj.2016.v13n3p438 URL:http://dx.doi.org/10.19044/esj.2016.v13n3p438

\begin{abstract}
Organic nitrogen concentration and nitrifying efficiency were related with aerobic reactor operation time, varying from zero up to 50 days and working as a Conventional Activated Sludge System, inoculated with sludge from a trickling filter system, packed with plastic media. The total nitrogen concentration at the beginning was adjusted to $70 \mathrm{mg} / \mathrm{dm}^{3}$, by means of lysine addition and, and the corresponding to dissolved oxygen stayed at least in $3 \mathrm{mg} / \mathrm{dm}^{3}$. The maximum nitrification efficiency for converting total nitrogen to nitrate was $86 \%$, and about 30 days, was not significantly increased and the alkalinity (expressed as $\mathrm{CaCO}_{3}$ ) was reduced from 425 down to $57 \mathrm{mg} / \mathrm{dm}^{3}$, decreasing about $7,50 \mathrm{mg} / \mathrm{dm}^{3}$ for each $\mathrm{mg} / \mathrm{dm}^{3}$ of organic nitrogen converted to nitrate.
\end{abstract}

Keywords: Nitrifying, alkalinity, dissolved oxygen, activated sludge, aerated reactor

\section{Resumen}

Se evaluó la relación entre la concentración de nitrógeno orgánico y la eficiencia nitrificadora en un Sistema de Lodos Activados en batch, empleando como inóculo el lodo secundario del sedimentador de un Sistema de Lecho Bacteriano Aerobio. La variable independiente fue el tiempo de operación del reactor aireado, que varió de desde cero hasta 50 días. La concentración de nitrógeno total al inicio se ajustó a $70 \mathrm{mg} / \mathrm{dm}^{3}$, mediante la adición de lisina y, la concentración de oxígeno disuelto se mantuvo en al 
menos $3 \mathrm{mg} / \mathrm{dm}^{3}$. La eficiencia máxima de nitrificación, oxidación del nitrógeno total a anión nitrato pasando previamente por nitrito, fue de $86 \%$, aunque desde el día No. 30, no aumenta significativamente, reduciéndose la alcalinidad (expresada como $\mathrm{CaCO}_{3}$ ) desde 425 hasta $57 \mathrm{mg} / \mathrm{dm}^{3}$, en una forma análoga a lo que lo hace la concentración de aniones nitrato y la eficiencia de nitrificación; o sea, que se redujo aproximadamente en 7,50 $\mathrm{mg} / \mathrm{dm}^{3}$ por cada $\mathrm{mg} / \mathrm{dm} 3$ de nitrógeno orgánico convertido en nitrato.

Palabras clave: Nitrificación, alcalinidad, oxígeno disuelto, lodos activados, reactor aireado

\section{INTRODUCCIÓN}

Los sistemas de tratamiento secundarios aerobios de las aguas residuales de origen doméstico, agropecuario, e industriales (con características orgánica apropiadas), en determinadas ocasiones son ineficientes en el desarrollo del proceso de nitrificación, generalmente debido al factor limitante del mismo, es decir, las relativamente baja velocidad específica de crecimiento de las nitrosomonas, bacterias responsables de la conversión del catión amonio $\left(\mathrm{NH}_{4}{ }^{+}\right)$en anión nitrito $\left(\mathrm{NO}_{2}{ }^{-}\right)$, con relación a las significativamente superior de las del género nitrobácter, que realizan la ulterior oxidación del $\mathrm{NO}_{2}{ }^{-}$a $\mathrm{NO}_{3}{ }^{-}$, vía aerobia.

$\mathrm{O}$ sea que, el problema de sistemas aerobios como el mencionado no sólo es la función que realizan como bioestabilizadores de la materia orgánica disuelta (Demanda Bioquímica de Oxígeno soluble), sino también la correspondiente bioxidación del nitrógeno amoniacal en nitritos y nitratos, para dar por concluida la oxidación de dicha materia orgánica y, la reducción de la agresividad ambiental de los residuos líquidos sometidos a los tratamientos secundarios, particularmente aerobios, o aireados en este caso.

\section{Nitrificación}

Los residuos líquidos presentan una elevada carga contaminante que responde, en gran parte, a la materia orgánica que contienen, en cuya composición se encuentran los compuestos de nitrógeno, principalmente aminoácidos. Las manifestaciones del nitrógeno de mayor interés en las mismas son el amoniacal y el total (APHA, AWWA, WPCF, 2000). El amoniaco es uno de los componentes transitorios en el agua, ya que es parte del ciclo del nitrógeno y se ve influido por la actividad biológica. Es un producto natural de la descomposición de los compuestos orgánicos nitrogenados. Las aguas superficiales no deben contener normalmente amoniaco. En general, la presencia de amoniaco libre o ion amonio se considera como una prueba química de contaminación reciente y peligrosa. 
Si el medio es aerobio, el nitrógeno amoniacal se transforma en nitritos (U.S. Environmental Protection Agency, 2000.

En resumen, el nitrógeno presente en el medio acuático puede existir en cuatro formas diferentes: nitrógeno orgánico, nitrógeno amoniacal, compuesto en forma de nitritos y compuestos en forma de nitratos. Esto está íntimamente relacionado con el ciclo del nitrógeno en la naturaleza, mostrado en el Cuadro 1 (Siles, 2008).

Cuadro 1. Ciclo del nitrógeno en la naturaleza.

\begin{tabular}{|c|c|}
\hline DE... & $\mathrm{A} \ldots$ \\
\hline $\mathrm{N}_{2}$ atmosférico & $\mathrm{N}_{\text {orgánico }}$ \\
\hline $\mathrm{N}_{\text {orgánico }}$ & $\mathrm{N}_{\text {amoniacal }}$ \\
\hline $\mathrm{N}_{\text {amoniacal }}$ & Nitrito (acción de las bacterias Nitrosomonas) \\
\hline Nitrito & Nitrato (acción de las bacterias Nitrobacter) \\
\hline Nitrato & $\mathrm{N}_{2}$ (acción de las bacterias denitrificantes \\
\hline
\end{tabular}

Fuente: Siles, 2008.

En el residuo líquido crudo están presentes las dos primeras. La descomposición por las bacterias transforma fácilmente el nitrógeno orgánico en amoniacal en la cantidad relativa de amoníaco presente es un indicativo de la edad del agua residual.

La transformación química denominada nitrificación se explica a través del hecho comprobado de que en los sistemas de tratamientos aerobios del agua residual, al bioxidarse la materia orgánica, vía metabolismo aerobio de las bacterias responsables de ello, es decir, aquellas que a través de la cadena respiratoria utilizan al oxígeno disuelto en el agua como último aceptor de hidrógeno y electrones, formándose en una primera etapa de unos 20 días, dióxido de carbono $\left(\mathrm{CO}_{2}\right)$ y agua $\left(\mathrm{H}_{2} \mathrm{O}\right)$, principalmente, fase conocida como carbonácea y; a partir de los 20 días se produce la conversión del nitrógeno amoniacal en nitritos y nitratos, secuencialmente, por la acción aerobia también de las bacterias de los géneros Nitrosomonas sp. (Figura 1), que producen nitritos y Nitrobacter sp. (Figura 2), que oxidan los nitritos a nitratos.

Entre las bacterias de acción nitrificante se encuentran, entre otras, Nitrosomonas sp., Nitrosolobus sp., Nitrosospira sp, oxidan el amoniaco a nitrito, y otro grupo, los nitratadores, por ejemplo Nitrobacter sp., Nitrococcus sp. y Nitrospina sp., que oxidan los nitritos a nitratos.

\section{Sistemas de Lodos Activados}

Un sistema de Lodos Activados se conforma por dos tipos de procesos, uno biológico (principal) seguido de uno físico, la sedimentación secundaria de la biomasa producida en el reactor biológico. El reactor biológico es un tanque en el que se suministra continuamente un determinado caudal del agua residual, así como un flujo de aire, que mantienen en suspensión y 
mezcla al denominado "licor mezclado", constituido por el agua residual con su materia orgánica que la caracteriza y una población microbiana formada por bacterias aerobias (en su mayoría) y una minoría de protozoarios, que mantienen el control del crecimiento excesivo de las primeras (Coello, Sales y Quiroga, 2003).

Con el empleo de un compresor o soplador de aire, este es introducido por la parte inferior del tanque de aireación y, en su trayectoria hacia arriba se produce la transferencia de masa a través de la cual, el oxígeno del aire (20\%) se disuelve en el líquido, manteniéndose concentraciones apropiadas del mismo en el licor, propiciándose el metabolismo aerobio (respiración) de las bacterias que bioxidan a los componentes orgánicos contenidos en el residuo líquido.

También, y en dependencia de factores como las concentraciones de nitrógeno orgánico y amoniacal, el tiempo medio de retención celular (edad del lodo), la alcalinidad, el $\mathrm{pH}$ y la temperatura, en el reactor aireado se desarrolla el proceso de nitrificación, pudiendo llegar hasta la conversión del nitrato en nitrógeno gaseoso (denitrificación).

El sedimentador secundario colocado a continuación es un tanque de flujo de líquido continuo, donde ocurre la decantación de los sólidos suspendidos, particularmente los volátiles (microorganismos), que fueron generados en el proceso de bioxidación aerobia de la materia orgánica. Constantemente se extrae líquido claro y sólo cada cierto tiempo, se purga lodo secundario.

Según Tchobanoglous y Crites (2000), el diseño del tanque de aireación de un Sistema de Lodos Activados, se basa en la cinética química de primer orden para la oxidación de la materia orgánica carbonácea, que es la que se tiene en cuenta para su dimensionamiento, principalmente a los factores, Tiempo medio de retención celular $(5-15$ d), concentración de sólidos suspendidos volátiles del licor mezclado $\left(1,5-3 \mathrm{~kg} / \mathrm{m}^{3}\right)$, coeficiente de rendimiento microbiano en el aprovechamiento del sustrato (0,4-0,8 $\mathrm{mg} / \mathrm{mg})$, la Demanda Bioquímica de Oxígeno de 5 días del afluente $(0,2-$ $\left.1,8 \mathrm{~kg} / \mathrm{m}^{3}\right)$ y del efluente $\left(\mathrm{kg} / \mathrm{m}^{3}\right) \mathrm{y}$, la constante de muerte $\left(0,04-0,075 \mathrm{~d}^{-}\right.$ $\left.{ }^{1}\right)$.

El objetivo principal de este estudio fue evaluar la relación entre el tiempo de operación, la concentración de nitrógeno orgánico y la eficiencia nitrificadora en Sistemas de Lodos Activados Convencionales. 


\section{DESARROLLO}

\section{Materiales y Métodos \\ Materiales}

Para la constitución del Sistema de Lodos Activados se utilizó:

- Tres recipientes cilíndricos circulares rectos, de $13,61 \mathrm{dm}^{3}$ de volumen cada uno, con un diámetro de la base de $17 \mathrm{~cm}$ y una altura de $60 \mathrm{~cm}$, es decir, suficientemente esbelto como para permitir un recorrido que propicie la disolución del oxígeno inyectado en el aire. La altura de líquido alcanzó los $54 \mathrm{~cm}$, quedando $6 \mathrm{~cm}$ libres.

- Un compresor de aire común, compresor de aire común Q Qed medido como 3 volúmenes de aire por volumen de medio por minuto, propició una concentración de oxígeno disuelto promedio de al menos $3 \mathrm{mg} / \mathrm{dm}^{3}$.

- Distribuidor de aire, cuyo reducido tamaño de sus agujeros garantiza el pequeño tamaño de las burbujas, propiciando una transferencia de oxígeno suficiente como para mantener la concentración deseada del mismo.

- El volumen de líquido de cada batch fue de 12,26 $\mathrm{dm}^{3}$, con una DBO de aproximadamente $700 \mathrm{mg} / \mathrm{dm}^{3} \mathrm{y}$, una concentración de nitrógeno total de $70 \mathrm{mg} / \mathrm{dm}^{3}$, ajustado con lisina.

\section{Métodos}

Se procedió a la puesta en marcha de cada uno de los tres reactores batch, previa adición del agua residual sintética enriquecida con lisina (calidad Técnica), la instalación del sistema de aireación con distribuidores de aire en la parte inferior de cada uno. El reactor se inoculó con 0,50 dm $\mathrm{dm}^{3}$ lodo secundario del sedimentador de un sistema de lecho bacteriano aerobio en funcionamiento.

El aire así suministrado mantuvo la condición del medio como la de un licor mezclado, midiéndose frecuentemente la concentración de oxígeno disuelto. la mezcla aire - oxígeno se introdujo a través de distribuidores de aire en la parte inferior de cada birreactor.

El muestreo para determinación de la concentración media de $\mathrm{NO}_{3}{ }^{-}$ se realizó por triplicado en días alternos, con excepción de los días del 32 al 50, que se ejecutó al cuarto día. Se tomó el para los cálculos de la nitrificación, la media de las tres muestras. En el caso de la alcalinidad, esta se determinó al inicio y al final (día número 50). Todos los análisis se realizaron empleando el Standard Methods AWWA, APHA, referido en la bibliografía. 


\section{Resultados y Discusión}

En el Cuadro 2 y Figura 1 se muestra el comportamiento de los valores medios de la eficiencia de nitrificación (entre 0 y 84\%) y el tiempo de operación del reactor batch (entre 0 y $50 \mathrm{~d}$ ), y de la alcalinidad (entre 425 y $\left.57 \mathrm{mg} / \mathrm{dm}^{3}\right)$, medidos como $\mathrm{Ca}\left(\mathrm{CO}_{3}\right)$.

Según los resultados, se observa que las eficiencias de nitrificación se redujeron significativamente al arribar a los días 20 - 22, lo que se corresponde aproximadamente con la teoría que soporta este fenómeno sin explicación cinética, según Metcalf y Eddy Inc. (1995) y Metcalf y Eddy Inc. (2011); comienzan a estabilizarse alrededor de los 30 días, a partir de los cuales los incrementos no son significativos, obteniéndose eficiencias de nitrificación cercanas al $84-86 \%$.

Cuadro 2. Comportamiento de los valores medios de la eficiencia de nitrificación y el tiempo de operación del reactor, así como de la alcalinidad

\begin{tabular}{|c|c|c|c|}
\hline $\begin{array}{l}\text { Tiempo de } \\
\text { reacción } \\
\text { (d) } \\
\end{array}$ & $\begin{array}{c}\mathrm{C}_{\text {media }}\left(\mathrm{NO}_{3}^{-}\right)_{\text {efluente }} \\
\left(\mathbf{m g} / \mathbf{d m}^{3}\right)\end{array}$ & $\begin{array}{c}\text { Eficiencia Media } \\
\text { de Nitrificación } \\
(\%)\end{array}$ & $\begin{array}{c}\text { Alcalinidad al } \mathrm{CaCO}_{3} \\
\left(\mathbf{m g} / \mathbf{d m}^{3}\right)\end{array}$ \\
\hline 0 & 10,97 & 15,67 & 425,00 \\
\hline 2 & 11,76 & 16,80 & 424,00 \\
\hline 4 & 10,88 & 15,54 & 427,00 \\
\hline 8 & 12,30 & 17,57 & 414,08 \\
\hline 12 & 14,27 & 20,39 & 400,79 \\
\hline 14 & 15,76 & 22,51 & 394,01 \\
\hline 16 & 21,81 & 31,16 & 372,26 \\
\hline 18 & 30,04 & 42,91 & 332,53 \\
\hline 20 & 33,59 & 47,99 & 296,8 \\
\hline 22 & 37,38 & 53,40 & 256,16 \\
\hline 24 & 42,45 & 60,64 & 221,57 \\
\hline 26 & 49,70 & 71,00 & 195,28 \\
\hline 28 & 55,44 & 79,20 & 178,25 \\
\hline 30 & 59,18 & 84,54 & 126,42 \\
\hline 32 & 60,17 & 85,96 & 83,19 \\
\hline 36 & 58,79 & 83,99 & 76,88 \\
\hline 40 & 59,24 & 84,63 & 66,44 \\
\hline 44 & 60,09 & 85,84 & 61,59 \\
\hline 48 & 58,75 & 83,93 & 55,07 \\
\hline 50 & 60,54 & 86,49 & 56,65 \\
\hline
\end{tabular}




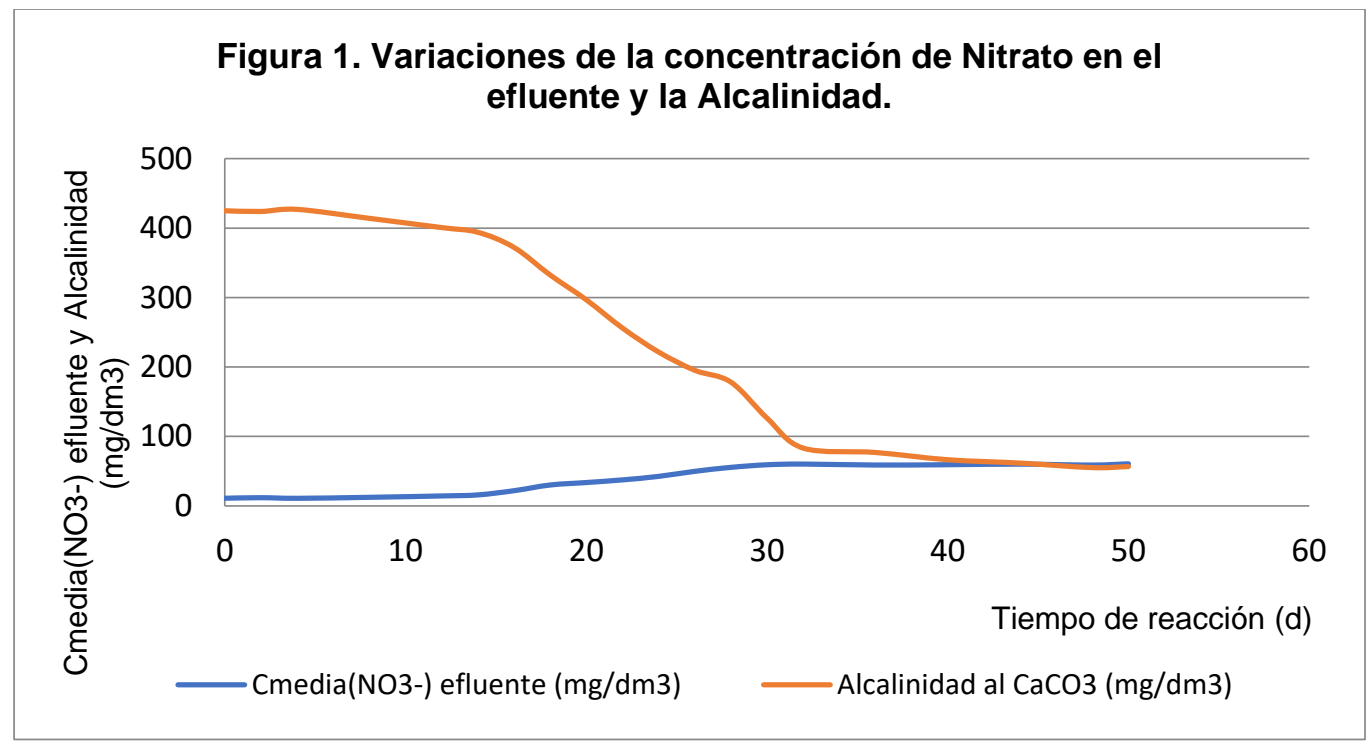

Elaborada por Leiva y otros (2015).

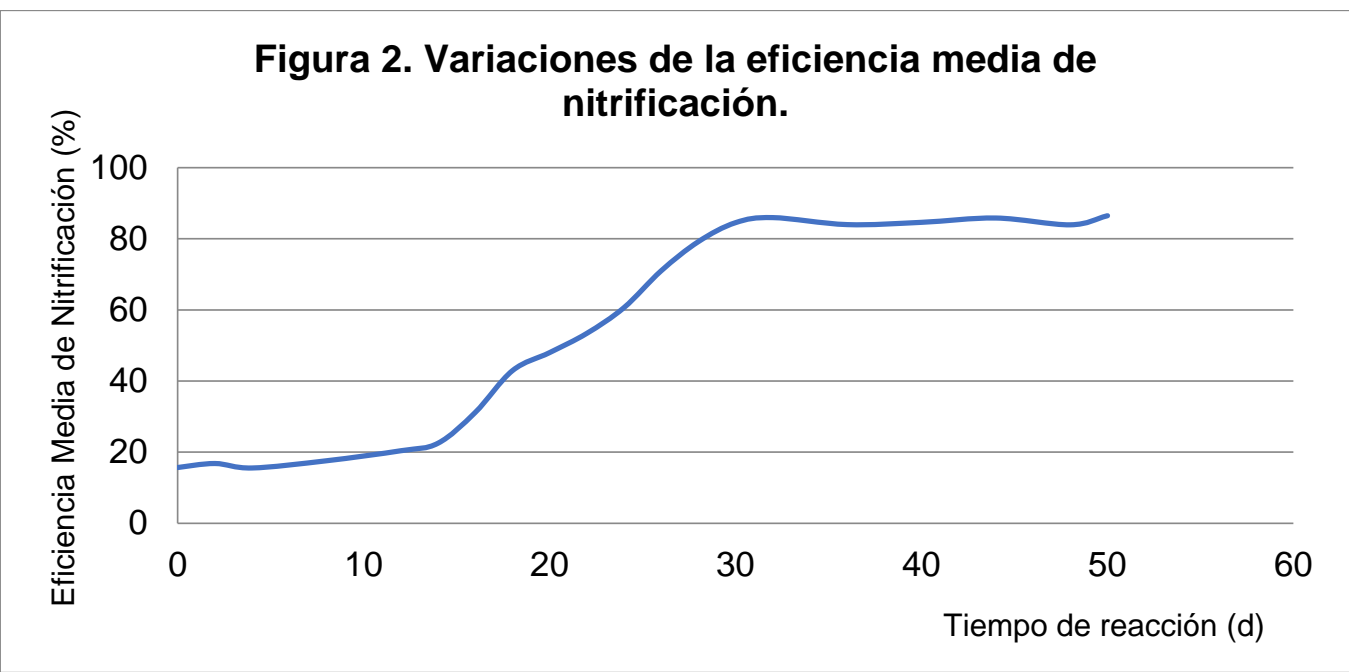

Elaborada por Leiva y otros (2015).

Otro resultado observado es que la alcalinidad se redujo a razón de $7,50 \mathrm{mg} / \mathrm{dm}^{3}$ de alcalinidad al $\mathrm{Ca}\left(\mathrm{CO}_{3}\right)$, por cada $\mathrm{mg} / \mathrm{dm}^{3}$ de nitrógeno total oxidado, comportamiento cercano al encontrado por Espinosa y otros (2014), reportado como $7,14 \mathrm{mg} / \mathrm{dm}^{3}$ por cada $\mathrm{mg} / \mathrm{dm}^{3}$ de nitrógeno total estabilizado. Otros investigadores como Siles y otros (2008), obtuvieron eficiencias de nitrificación entre 75 y 90\%, en sistemas de lodos activados convencionales, aunque sin incrementar el nitrógeno total del agua residual, como sí se implementó en este estudio, y obteniéndose eficiencias de nitrificación del 86\%. Se colige que con una concentración inicial de al 
menos $425 \mathrm{mg} / \mathrm{dm}^{3}$ de alcalinidad (como $\mathrm{CaCO}_{3}$ ), esta se reduce y estabiliza de forma similar a lo que lo hace la concentración de aniones nitrato y por lo tanto, la eficiencia de nitrificación.

Manteniendo una concentración de oxígeno disuelto de al menos 3,0 $\mathrm{mg} / \mathrm{dm}^{3}$, aun enriqueciendo en nitrógeno total, en este caso con lisina, se obtienen niveles de nitrificación satisfactorios. También determinó un incremento de la concentración de anión nitrato en la medida en que aumenta la alcalinidad, partiendo desde 5,2 hasta $31,54 \mathrm{mg} / \mathrm{dm}^{3}$, comportándose correspondientemente con la eficiencia de nitrificación.

\section{CONCLUSION}

- Con tiempos de operación en un reactor batch completamente mezclado, se obtienen niveles de nitrificación relativamente altos (85\%) a los 30 días, aun enriqueciendo por sobre lo habitual, al agua residual que actúa como sustrato, con nitrógeno procedente de la lisina (hasta $70 \mathrm{mg} / \mathrm{dm}^{3}$ de nitrógeno orgánico total).

- A partir de los 30 días, la eficiencia de nitrificación no aumenta significativamente, estabilizándose en los alrededores del referido $85 \%$

- La alcalinidad del sistema se redujo a razón de $7,50 \mathrm{mg} / \mathrm{dm}^{3}$, por cada $\mathrm{mg} / \mathrm{dm}^{3}$ de nitrógeno total nitrificado (oxidado).

- Los resultados satisfactorios sobre nitrificación se obtuvieron manteniendo una concentración mínima de oxígeno disuelto de 3,0 $\mathrm{mg} / \mathrm{dm}^{3}$.

\section{References:}

1. APHA, AWWA, WPCF. 2000. Nitrogen ammonia phenate method. En: Standard methods for the examination of water and wastewater. Washington DC.

2. Coello, M., Sales, D. y Quiroga, J.M. 2003. Evolución de un sistema de lodos activos sin aporte de alimentación. Ingeniería del Agua, Vol. 10. No 1, España.

3. Espinosa, M. A., Bravo, O. Ortega, M. e Hidalgo, A. 2014. Evaluación de la nitrificación a través de perfiles operacionales en un reactor aerobio.

4. Leiva, A. 2015. Relación entre el tiempo de operación, la concentración de nitrógeno orgánico y la eficiencia nitrificadora en un sistema de lodos activados en batch. II Congreso internacional de Ingeniería Ambiental, UTE, Santo Domingo de los Tsáchilas, Ecuador.

5. Metcalf y Eddy Inc. 1995. Wastewater Engineering: Treatment and Reuse. Ed. McGraw - Hill. 4th Edition, New York, USA. 
6. Metcalf y Eddy. 2011. Tratamiento Avanzado de Agua Residual. Ed. Zhugo Flores, New York, USA.

7. Siles, E., Monforte. J., Estrany, F. y Oliver, R. 2008. Eliminación del nitrógeno amoniacal en aguas residuales sanitarias. Técnica Industrial. TI 273. Madrid, España.

8. Tchobanoglous, G. y Crites, R. 2000. Tratamiento de aguas residuales en pequeñas poblaciones. Ed. McGraw - Hill. New York, USA.

9. U.S. Environmental Protection Agency. 2000. Folleto informativo de tecnologías de las aguas residuales. EPA Washington DC:832-F00024. 